\title{
Research on the Reform of Distribution Incentive Mechanism of Scientific and Technological Personnel in Taizhou under the Innovation Development
}

\author{
Li Guannan \\ Taizhou Polytechnie College, Science and Technology Department \\ Jiangsu Taizhou 225300
}

\begin{abstract}
This article uses the method of current situation analysis-problem found-problem solution, aims at sorting out the relationship of innovation development, scientific and technological personnel and incentive mechanism, putting forward opinions and suggestions for the incentive mechanism reform of scientific and technological personnel in Taizhou. The research shows that the incentive mechanism is an important external factor that affects the innovation potential of scientific and technological personnel. It plays an important role in promoting the innovation potential of scientific and technological personnel. In the context of innovation-driven development, Taizhou scientific and technological personnel distribution incentive mechanism reform is imperative. The study conduct around the relationship of the innovation development, scientific and technological personnel and the incentive mechanism, which is the innovation of this article.
\end{abstract}

Keywords-innovation-driven; incentive mechanism; scientific and technological personnel

\section{INTRODUCTION}

Innovation-driven is the inevitable choice of China's economic and social development, and technology is a necessary condition for innovation, talent is the fundamental innovation. In 2013, Taizhou won the national innovation pilot cities, as the youngest city in central Jiangsu Province, Taizhou has a greater potential for innovation development advantages, but there are also some disadvantages, in the system, there are imperfect problems in the allocation of scientific and technical personnel for incentive mechanism, which need to be reformed and perfected. Taizhou achieves innovation-driven development of the reality of the need for scientific and technological personnel to allocate incentive system reform and improvement, scientific and technological personnel distribution incentive for Taizhou to achieve Innovation Development also has an important role in promoting.

\section{THEORETICAL OVERVIEW}

\section{A. Innovation theory}

The theory of modern innovation was first proposed by American economist Joseph Schumpeter. In 1912, Schumpeter published the book "Economic Development Theory", putting forward the "innovation" and its role in economic development, a sensation of the Western economic circles. He believes that development is the economic cycle of the track changes, but also on the balance of disruption and break. Here are the "change", "disturb" and "break", means innovation. Thus, only innovation will make the above two issues be effectively resolved. This is because innovation has roughly the following two functions: First, by continuously increasing the productivity of a single or synthetic factor to offset the trend of diminishing single factor or total factor returns as a result of an increase in the number of factor inputs; Second, through the new combination of factors to break through the economic development sooner or later.

Nobel Prize winner, development economics leader Arthur Lewis Ja's inflection point theory to understand the innovation drive also has a great help. He believes that the basic elements of economic development, including natural resources, capital, intelligence and technology, in the marginal effect of diminishing law under the effect of natural resources and capital contribution to economic development is decreasing, so in the long run, economic development depends on the human intelligence and technology ". Therefore, we must change the resource-dependent, capital-dependent development of the way, and the development of human resources and technology, the only way to make economic growth to obtain sustained development momentum and source.

Michael Porter is similar to Lewis's thought and logic, the theory of national competitive advantage suggests that the process of international competition in one country can be divided into four stages: factor driving, investment driving, innovation driving and wealth drive. The source of national competitive advantage lies in the vitality of enterprises in each industry. The development of the industry can only push the value chain from the low level to the high level continuous from the promotion of the economy and the promotion of the capitalization stage to the innovation promotion stage. In the stage of innovation-driven, due to the scarcity of factors of production to further improve. Therefore, how to effectively improve the efficiency of resource production knowledge and methods become more important, through innovation to increase the level of per capita production, promoting economic growth as the dominant way [1] 


\section{B. Incentive theory}

\section{1) The Definition and Connotation of Incentive}

Incentive (mot1vate) in English is intended to "refers to the stimulus, induction and give motivation, triggering an individual behavior," in the Chinese dictionary in the interpretation of "agitation, to stimulate the excitement or cheer", in English on the incentive words Of the interpretation of the same, all through the effective operation of a certain incentive or induce others to make it into a high motivation for the realization of a goal to forge ahead. The research on motivation is more common in the field of psychology and management, and the understanding and definition of motivation are different in different fields [2].

From a psychological point of view, human behavior is motivated, and human motivation originated from human needs, a demand if not be met, it will lead to inner tension, which led to the individual to take a certain behavior to meet the demand to lift or reduce the degree of tension. From this point of view, the incentive is to stimulate people's motives, encouraging people to play the internal driving force fully, towards the desired goal, to take action psychological process.

From the management point of view, the incentive is a management system in an organization system, it through the rational use of various resources and means to guide, stimulate and strengthen the manager's motivation to achieve the objectives of the management process, including the stimulus, the encouragement, the interest to induce the meaning, the restraint and the naturalization, the reward and the punishment are the two most basic incentives [3].

\section{2) The role and factors of motivation}

Incentive plays an important role in human resource management, mainly in three aspects: First, the incentive can mobilize the enthusiasm of the staff, dig their work potential. Second, incentives can promote the growth of employees and self-improvement. In addition to learning and training, motivation is one of the effective ways to improve the quality and ability of employees. Third, incentives can enhance the collective awareness of members to help organizations better achieve their goals. Giving members of the organization a certain positive incentive, can inspire members of the fighting spirit and potential to help them to work creatively. Giving the members of the organization a certain negative incentive, can effectively prevent the interests of the organization of behavior. This will help members to enhance the collective consciousness, and promote organizational goals to achieve.

The motivating factor is the factor that can stimulate the behavior of the motivated person and thus motivate it. It represents the most essential demand of the motivated person. Only when the incentive activity or goal is set to satisfy some kind of incentive factor, Will make the incentive to produce satisfaction, resulting in behavioral driving force [4]. In general, incentive factors can be divided into three categories: First, the characteristics of the work itself with the incentive factors. Such as the working environment, difficulty, treatment, etc. .; Second, the organizational characteristics related to the incentive factors. Including organizational awareness, organizational structure, interpersonal relationships within the organization, etc. .; third, and employee characteristics related to the incentive factors. Mainly related to the work of the staff pressure, work interest, work sense of accomplishment and so on.

\section{3) The process and mechanism of motivation}

The process of motivation is summarized as follows: internal and external stimulus leads to the imbalance of individual demand, and then produce a strong motivation and cause the individual to produce positive behavior, positive behavior to promote the realization of the goal, to achieve the goal after the full satisfaction and the formation of new internal and external stimuli, Together with the original internal and external stimuli lead to new urgent needs, The incentive process is such a cycle, continuous.

Incentive mechanism, also known as incentive system, integrated research has been defined as incentives: organizational managers according to organizational goals, in the analysis of the needs of members of the organization and motives, based on the rational allocation of organizational resources and management of the optimal combination, Formulate and implement a set of work systems and work norms that can guide and strengthen the organization's thinking, motivation and behavior over a long period of time. In general, the incentive mechanism has the effect of promoting and weakening the organization. The role of encouragement refers to the incentive mechanism to the staff of a certain organization in line with the expectations of the behavior has repeatedly strengthened, increasing the role of the organization continue to grow and develop. The weak effect of the incentive mechanism is that, because there is a motivating factor in the incentive mechanism, the organization does not show the behavior expected by the members.

\section{AN ANALYSIS OF THE INCENTIVE MECHANISM OF SCIENTIFIC AND TECHNICAL PERSONNEL IN TAIZHOU}

\section{A. Scientific and technical personnel incentive factors}

Before researching the distribution incentive mechanism of scientific and technical personnel, we must first clarify the characteristics and incentive needs of this group of scientific and technical personnel, and find out which factors can stimulate the behavior of scientific and technological personnel, so as to mobilize their enthusiasm, so that the scientific and technological personnel have a sense of satisfaction Behavioral impetus [5]. The incentive needs of scientific and technological personnel mainly include three kinds, namely, material demand, recognized demand, self-development and realization of the demand, which recognized the needs and self-development needs to achieve spiritual needs, the impact of these factors is the scientific and technological personnel Motivating factors.

\section{1) Material needs}

According to Maslow's theory of needs hierarchy, physiological needs are the most basic needs of mankind, mainly including the basic needs of basic necessities, which are often called "material needs" [6]. Scientific and technical personnel as an integral part of the social staff, with the "social people" nature, first of all need to meet their material needs. Factors that affect the material needs of scientific and technological personnel include salaries, work-related incentives, and so on. 


\section{2) Recognized demand}

According to McLellan's "high achievement needs theory", people with high achievement demand and light material, their enthusiasm depends mainly on the high level of spiritual needs to meet, and less affected by material factors. For the scientific and technical personnel, in the realization of the basic material needs, the material incentives than the temptation of spiritual incentives to be much smaller, social identity is their pursuit of the biggest goal, they want their work to get the unit and organization and the upper body appreciation and trust, by the community's broad and full respect. Factors affect the need for scientific and technical personnel to be identified mainly include the trust and recognition of leaders and colleagues, various awards and honors related to the work of science and technology.

\section{3) Self-development and implementation needs}

According to Maslow's theory of needs hierarchy, selfdevelopment and realization of the demand has been the highest level of human needs. When the other needs of the people are met, they will produce self-realization needs. Selfrealization needs is that people have the full play to their potential, to achieve their own value of life, and strive to become the driving force of the ideal. The vast majority of scientific and technical personnel have been formal higher education, their knowledge level is relatively high, more open horizons, and personal development has a clear positioning and clear needs. The demand for self-development of scientific and technical personnel is reflected in the strong desire to participate in continuing education and professional conference learning, on the other hand reflected in the scientific research funding, scientific research equipment, and support staff deployment and so on. Factors that affect the demand for selfdevelopment of scientific and technological personnel mainly include participation in training, professional meetings, professional training opportunities, scientific research conditions and funding protection. Self-realization is a higher level of demand than self-development, and is entirely spiritual. Many scientific and technical personnel of the pursuit of science is not in order to obtain material or other aspects of the interests, not only in order to get social recognition, but the cause of science is full of great enthusiasm. This is closely related to their values held by science. They only regard scientific honor and access to material interests as a by-product, and their self-realization is manifested in recognizing their scientific achievements and helping them to pursue scientific research Peak experience.

\section{B. Analysis on the Incentive Mechanism of Scientific and Technical Personnel Distribution in Taizhou}

Incentive mechanism refers to the sum of the motivations of the incentive system in the organizational system through the interaction between the incentive factor and the incentive object. In the early years, foreign scholars pointed out that the scientific community must, like other academics, establish a good mechanism of operation, taking into account the status of scientific and technological personnel, and pay compensation according to the level, providing incentives for the success of those who have the ability to create their own role opportunity.
To stimulate the inherent potential of scientific and technological personnel to meet their needs at all levels, we must establish a reasonable allocation of scientific and technological personnel incentive mechanism.

\section{1) Taizhou Science and Technology Personnel and Its} Distribution Incentive Mechanism

Relative to other prefecture-level cities in Jiangsu Province, Taizhou City, relatively late, is a new industrial city, in the country, the province's visibility is not high. In addition, Taizhou is located in the middle of Jiangsu Province, relatively speaking, the geographical location is more closed, few foreign population, institutions of higher learning, research institutes and key large and medium-sized enterprises in small numbers, so Taizhou scientific and technical personnel of the original stock less. In recent years, some undergraduate colleges in Taizhou established an independent college, Taizhou, the number of institutions of higher learning and research institutes have increased. In May 2009, China's only state-level medical city was officially established in Taizhou, and later established Taizhou City Pharmaceutical High-tech Zone, a number of large and medium-sized enterprises in this establishment. Taizhou, the number of scientific and technological personnel are also increasing. Taizhou from the government to institutions of higher learning and scientific research institutes and then to the enterprise, more and more aware of the importance of talent, introduced a number of support policies to optimize the allocation of scientific and technological personnel incentive mechanism.

In 2009, the Taizhou municipal government promulgated the "Taizhou City, the introduction of high-level innovative entrepreneurship program implementation approach" and "Taizhou overseas talents introduction plan implementation opinions", in order to attract innovative entrepreneurship technology talent opened the policy channel. In 2010, the introduction of the "Taizhou high-level innovation and entrepreneurship talent introduction plan implementation details", developed to attract high-level scientific and technological personnel of the specific methods, announced the city level to attract high-level scientific and technological talent distribution incentive policy. Taizhou colleges and universities also put forward the school level of science and technology talent to introduce preferential policies to improve the highlevel scientific and technological personnel of the various treatment and incentive conditions, including home fees, purchase subsidies, spouse work arrangements, scientific research start funding. In 2011, the Company promulgated the Provisions on the Measures for Accelerating the Construction of the Talent Special Zone of China Medical City in 2011, and promulgated the Regulations on the Implementation of the Provisions on the Construction of the Talent Special Zone of China Medical City in 2012. For the Chinese Medical City, especially one of the high-tech enterprises to develop special policies and special mechanisms to explore the establishment of personnel training and development, evaluation of the use of mobile allocation and incentive and other important mechanisms.

2) Problems in the Incentive Mechanism of Scientific and Technical Personnel Distribution in Taizhou 
In recent years, Taizhou has continuously increased the importance of scientific and technological personnel, especially in 2013 was identified as the first 47 countries after the pilot cities, more aware of the core role of scientific and technological personnel in innovation and entrepreneurship, the allocation of scientific and technological personnel incentives Mechanism has been improved, but there are still deep-seated problems

a) Deep mechanism is not perfect. Although Taizhou has introduced a series of policies and rules to introduce innovative talents, but deep-level mechanism is still not perfect, making these talent policy can not give full play to its incentive role. At present, Taizhou City has a total of five institutions of higher learning, each university has launched its own talent to attract incentive policies, but the current five colleges and universities in the post are not full-time research posts, recruit high-level talent into the school in addition to scientific research work, As well as teaching tasks, and even student management and other complex issues, affecting their research work, the introduction of talent policy incentives have weakened. On the other hand, colleges and universities, universities and universities, research institutes, research institutes and enterprises between the lack of innovative cooperation platform, making many scientific and technical personnel only stay in the theoretical stage, affecting the transformation of scientific and technological achievements into real productive forces, and then industrialization. As Taizhou's production and research collaboration with a small number of platform, production and research cooperation with the external cooperation, and Taizhou local universities and research institutes to cooperate with the ability of enterprise innovation is weak. The ability of scientific and technological personnel has not been fully brought into play, the incentive mechanism does not really play a role.

b) The lack of a soft environment to play a role. Taizhou scientific and technological personnel of the existing allocation of incentive policy mechanism is still not fully considered and recognized the characteristics and needs of scientific and technological personnel. Scientific and technical personnel generally have a strong personality, do not want to be controlled by others; have a strong sense of autonomy, with independent values. In terms of demand, the scientific and technical personnel to pursue the realization of self-worth, strong desire for success, not only to meet the material needs and security needs to meet the economic interests, and the pursuit of recognition and respect for the needs of selfrealization of the spirit of the need to enjoy, In the internal satisfaction [7]. Hoping that the professional progress and can constantly update the knowledge, require greater autonomy and decision-making power, pay attention to self-guidance and management; attention to a harmonious working environment, hope to get enough understanding and support in the work. However, due to the late development of Taizhou, soft environment construction is not perfect. Scientific and technical personnel in the work of the restrictions are still more, "official standard" thinking still exists, the work environment is not enough pragmatic, scientific and technical personnel are not fully respected, trust and recognition, work autonomy has not been fully, Thus affecting its qualifications, inspiration and innovation ability to play. Scientific and technical personnel training and development mechanism is not perfect, many units of scientific and technical personnel re-use of light training, scientific and technological personnel lack of participation in education and training and career development opportunities, can only repeat the original knowledge structure, do not see their own and the organization's common growth, Do not see the organization's shared vision goals, it is difficult to form incentives. Some talent policy, the high wages, high welfare as the most important means to attract scientific and technological personnel, ignoring the psychological income of scientific and technological personnel, not taking into account the needs of scientific and technological personnel have risen to a higher level, the incentive effect diminished.

c) Policy lack of popularity. Taizhou existing scientific and technical personnel distribution incentive policies are mostly for high-level talent, the lack of popularity, very few for the majority of ordinary scientific and technical personnel. There are still many scientific and technical personnel of the low wage income, pay can not reflect their contribution or enjoy unfair pay, which to a large extent affected their work in the initiative, initiative and creativity.

\section{RESEARCH ON THE REFORM OF SCIENCE AND TECHNOLOGY PERSONNEL 'S INCENTIVE MECHANISM IN TAIZHOU}

According to the above analysis, Taizhou existing scientific and technical personnel distribution incentive mechanism there are some problems, affecting the effective role of the mechanism. Innovation-driven development is "peopleoriented" development, talent is the innovation of the people's intelligence is the development of innovation under the first production factors. Incentive and behavior exist between the intrinsic, essential and inevitable link, through the incentive mechanism to mobilize the enthusiasm of the main body of scientific and technological innovation, give full play to the potential of scientific and technological personnel, to promote the development of science and technology is very important. Therefore, in the context of innovation-driven development, Taizhou scientific and technological personnel distribution incentive mechanism reform is imperative. Taizhou to achieve innovation-driven development of the reality of the need for scientific and technological personnel to allocate incentive system reform and improvement, at the same time, scientific and technological personnel distribution incentive mechanism for Taizhou to achieve innovation development has an important role in promoting.

\section{A. The Overall Train of Thought of Taizhou's Scientific and Technical Personnel Allocation Incentive Mechanism Reform}

On the one hand, Taizhou scientific and technological personnel distribution incentive mechanism reform to innovation-driven strategy as the guiding ideology, a clear allocation of incentive mechanism reform goal is to mobilize the scientific and technological personnel in the work of the initiative, initiative and creativity, so that they give full play to their qualifications and Potential, to play a creative, to promote 
innovation development in Taizhou. On the other hand, Taizhou scientific and technological personnel distribution incentive mechanism reform should adhere to the "peopleoriented" principle, starting from the needs of scientific and technological personnel, taking full account of the incentive needs of scientific and technological personnel, grasp the factors that affect the enthusiasm of scientific and technological personnel, and strive to meet the needs of scientific and technological personnel They really feel the strength of the use, only show, labor and income, merit prizes, and thus to mobilize the potential of their creation.

\section{B. Suggestions on the Reform of Taizhou Science and Technology Personnel 's Incentive Mechanism}

1) Improve the deep mechanism to make the incentive policy feasible

Colleges and universities level, to promote the reform of college posts, increase the full-time scientific research post set. For the institutions of higher learning, especially high-level talent to create research and development conditions and the environment so that they have sufficient time and energy to carry out scientific research and innovation work, give full play to the government and schools to introduce high-level talent policy incentives. Enterprises and research institutes level, the establishment of colleges and universities, universities and research institutes, research institutes and enterprises between the collaborative innovation development platform to promote scientific research and scientific and technological achievements into real productive forces, and then industrialization, To achieve economic benefits, so that science and technology $\mathrm{R} \& \mathrm{D}$ workers have a sense of accomplishment, to stimulate greater potential, generate incentives.

\section{2) People - oriented, strengthen the incentive environment to build}

Attention to the work of the soft environment of scientific and technological personnel construction, fully consider and recognize the characteristics and needs of scientific and technological personnel. Both universities, research institutes and enterprises are not only to meet the material needs and security needs of scientific and technical personnel, but also to meet their needs and self-fulfilling needs. People-oriented, give them full respect and trust, research work to give them greater autonomy and decision-making power, to stimulate their innovation, creativity to play. Attention to the cultivation of scientific and technological personnel, to provide them with more opportunities for learning, the establishment of a common vision goals, so that scientific and technological personnel to see their own and the common development of the organization, resulting in incentives.

3) Improve the popularity of incentives, stimulate the potential of ordinary scientific and technological personnel

From the policy and institutional level, to improve the popularity of distribution incentives, so that the allocation of incentive policies apply to more scientific and technological personnel. On the one hand, to enhance the level of income of ordinary scientific and technological personnel, so that most of the scientific and technological personnel are able to get higher than the basic industry, the basic salary to meet their material needs, and then stimulate their self-realization needs. On the other hand, increasing the types and quantities of science and technology incentives, stimulating the potential of ordinary scientific and technical personnel, mobilizing the enthusiasm of more scientific and technological personnel, so that they have a greater incentive to carry out innovative research and technology development, so that more scientific and technical personnel to join the innovation In development.

\section{CONCLUSION}

Innovation development, scientific and technological progress on economic growth has a strong driving effect, which requires people to achieve. The innovation potential of scientific and technological personnel not only with their talent, knowledge and other internal factors, but also with the external environmental factors have a great relationship. Among them, the distribution incentive mechanism is an important external factors, it is the innovation potential of scientific and technological personnel play an important role in promoting. Taizhou as a new and innovative pilot cities, with greater potential for innovation development advantages, but there are also some problems. For example, the scientific and technical personnel distribution incentive mechanism is not perfect, the lack of the role of the soft environment, the lack of policy and so on. In the context of innovation-driven development, the reform of the distribution system for scientific and technical personnel in Taizhou is necessary. Reform should take the innovation-driven strategy as the guiding ideology, adhere to the "people-oriented" principle, improve the deep mechanism, strengthen the soft environment construction, improve the policy of universal, meeting the scientific and technological personnel of the individual material and spiritual incentive needs, to mobilize its enthusiasm and initiative, to play a creative, scientific and technological personnel to achieve the individual and the common development of the city.

\section{ACKNOWLEDGMENT}

Fund project : 2016 Taizhou Soft Science Research Project "Research on the Reform of Distribution Incentive Mechanism of Scientific and Technical Personnel in Taizhou under the innovation development" (Number : RKX201626)

About the Author: Li Guannan(1981-), From Hengshui, Hebei Province, Taizhou Polytechnic College lecturer, master, and research direction are science and technology management, education management and industrial economy.

\section{REFERENCES}

[1] Li Dongxing. Innovation-driven development strategy research [J]. Journal of the Central Institute of Social Sciences, 2013 (2).

[2] Xu Zhaoming. Enterprise performance and incentive mechanism [M]. China Tax Press, 2006.

[3] Yin Zhihong, Ye Min. Management Psychology [M]. Beijing University of Posts and Telecommunications Press, 2007.

[4] Su Mingcheng, Zhang Xiangqian. Incentive theory development and trend analysis [J]. Science and Technology Management Research, 2009

[5] Li Yingling. Enterprise science and technological personnel incentive theory application $[\mathrm{J}]$.Enterprises research, 2012 (2).

[6] Zhang Yan, Wu Nanzhong.Study on incentive mechanism of scientific and technological personnel based on six forces [J]. Journal of Chongqing Radio \& TV University, 2013 (5). 
[7] Zhang Ling. On the transformation of scientific and technological personnel in the transformation of institutions [J]. Food Circulation
Technology, 2013 (1). 